\title{
Large urban freight traffic generators: Opportunities for city logistics initiatives
}

\author{
Miguel Jaller ${ }^{\mathrm{a}}$ \\ University of California, Davis
}

\author{
Xiaokun (Cara) Wang ${ }^{\mathrm{b}}$ \\ Rensselaer Polytechnic Institute
}

\author{
Jose Holguín-Veras ${ }^{c}$ \\ Rensselaer Polytechnic Institute
}

\begin{abstract}
This paper develops procedures to identify and quantify the role played by large urban freight traffic generators as contributors of truck traffic in metropolitan areas. Although ports, container terminals, and other industrial sites are usually associated with large generations of truck trips, they only represent a small proportion of the total trips produced and attracted in large metropolitan areas. This paper analyzes the importance of other facilities such as ordinary businesses or buildings that individually or collectively (clusters) generate a large proportion of truck traffic. The paper discusses the opportunities of these large traffic generators for city logistics initiatives. In addition, the paper introduces two effective and complementary procedures to identify these generators using freight trip generation models estimated by the authors.
\end{abstract}

Keywords: Freight trip generation, large traffic generators, city logistics

\section{$1 \quad$ Introduction}

Around the world, urban areas have been experiencing rapid development and expansion. Increased economic activities demand more consumer goods and services, all of which need to be transported from production sites to where they are needed. As a consequence, both private and commercial vehicle demand has exploded, increasing from about 130 million registrations worldwide in the 1960s (Bureau of Transportation Statistics 2010) to more than a billion vehicles in operation in 2010 (Sousanis 2011). Although vital for the industrial, commercial and leisure activities that foster economic vitality, these vehicles also generate problems, such as traffic congestion and environmental pollution. It is estimated that during 2010 in the United States, travelers suffered travel delays of 4.8 billion hours, using an extra 1.9 billion gallons of fuel, for a total "congestion cost" of about $\$ 101$ billion. The costs for truck congestion alone accounted for about $\$ 23$ billion, a cost that impacts consumers when translated into higher prices (Texas Transportation Institute 2011).

New York City has one of the largest concentrations of transportation facilities in the world, with dozens of container terminals, intermodal yards, major airports, and a large public transportation and road network, and it is one of America's most congested cities. A contributing factor to the congestion experienced in the city relates to the large freight truck traffic needed to support its vibrant economy.

\author{
amjaller@ucdavis.edu \\ bwangx18@rpi.edu \\ jhv@rpi.edu \\ Copyright 2015 Miguel Jaller, Xiaokun (Cara) Wang, and Jose Holguín-Veras \\ http://dx.doi.org/10.5198/jtlu.2015.406 \\ ISSN: 1938-7849 | Licensed under the Creative Commons Attribution - NonCommercial License 3.0.
}

The Journal of Transport and Land Use is the official journal of the World Society for Transport and Land Use (WSTLUR) and is published and sponsored by the University of Minnesota Center for Transportation Studies. 
Table 1 shows the estimated freight truck trips attracted (FTA) and freight truck trips produced (FTP) in the city. FTA is defined as the truck trips bringing the product shipments or deliveries that an establishment receives in a period of time. FTP refers to the number of truck trips that originate at an establishment and are used to transport any goods shipped or sent to other companies or customers in a period of time. The estimates in Table 1 are based on freight trip generation (FTG) models estimated by the authors using a freight trip generation survey from a sample of receiver and carrier business in New York (Holguín-Veras et al. 2013). As shown, Manhattan—with an area of 23 square miles or 8 percent of the city - accounts for about half of the FTG in the city, with about 182,427 daily freight truck trips attracted and 161,144 produced. It comes as no surprise that in 2011, the New York-Newark urban area ranked third in the United States in total delays, after Washington, DC (first), and Los Angeles-Long Beach-Santa Ana and San Francisco-Oakland (second), and first in truck delays with a cost of $\$ 2.5$ billion.

Table 1: Freight trip generation in New York City.

\begin{tabular}{|l|c|c|c|c|c|c|c|}
\hline County & Population & Establishments & $\begin{array}{c}\text { Estimated } \\
\text { employment }\end{array}$ & $\begin{array}{c}\text { Estimated } \\
\text { daily FTA }\end{array}$ & $\begin{array}{c}\text { Percentage of total } \\
\text { FTA per day }\end{array}$ & $\begin{array}{c}\text { Estimated } \\
\text { daily FTP }\end{array}$ & $\begin{array}{c}\text { Percentage of total } \\
\text { FTP per day }\end{array}$ \\
\hline Bronx & $1,332,650$ & 15,528 & 224,179 & 26,320 & $7 \%$ & 26,838 & $8 \%$ \\
\hline Brooklyn & $2,465,326$ & 44,043 & 521,992 & 75,865 & $20 \%$ & 73,431 & $21 \%$ \\
\hline Manhattan & $1,537,195$ & 102,597 & $2,062,079$ & 182,427 & $49 \%$ & 161,144 & $47 \%$ \\
\hline Queens & $2,229,379$ & 41,551 & 518,953 & 71,447 & $19 \%$ & 68,883 & $20 \%$ \\
\hline Staten Island & 443,728 & 8,376 & 100,975 & 14,464 & $4 \%$ & 12,910 & $4 \%$ \\
\hline Grand Total & $8,008,278$ & 212,095 & $3,428,177$ & 370,522 & $100 \%$ & 343,206 & $100 \%$ \\
\hline
\end{tabular}

Notes: FTA = Freight trips attracted; FTP = Freight trips produced

Estimated by the authors (Holguin-Veras et al. 2013)

The detrimental effects generated by these urban freight movements, which can threaten quality of life, have required the implementation of traffic management and city logistics strategies. Different policies for both passenger and freight transportation have been adopted or pilot tested around the world, with mixed results. Examples include: infrastructure management, parking/loading areas management, vehicle access restrictions, time access restriction, lane management, traffic control, taxation and incentives-related strategies, park-and-ride systems, and off-hour deliveries, among others (Allen et al. 2000; Allen et al. 2003; Kjaersgaard and Jensen 2003; Geroliminis and Daganzo 2005; BESTUFS 2007; Dablanc 2007; Quak 2008; START 2009; SUGAR 2011; Dablanc et al. 2013; Holguín-Veras et al. 2014a; Holguín-Veras et al. 2014b). In New York City, for example, the Office of Freight Mobility of the New York City Department of Transportation (NYCDOT) in partnership with academic institutions is evaluating different initiatives to improve truck traffic. These policies (e.g., a program to foster a shift of truck traffic to the off-hours, curb-side and parking management, and freight villages, among others) are intended to achieve reduced congestion and a more efficient use of the transportation infrastructure.

Key to designing the above initiatives is an understanding and quantification of freight trip generation patterns. In this context, this paper builds on recent work conducted by the authors (Holguín-Veras et al. 2011; Lawson et al. 2012; Holguín-Veras et al. 2013; Holguín-Veras et al. 2013; Jaller et al. 2013) and explores the importance of facilities that generate a large number of truck trips, and therefore also produce highly concentrated traffic impacts (congestion, noise, pollution). Although the majority of the public, as wells as transportation practitioners and planners, associate large freight traffic generators with marine ports, container terminals or other industrial sites, these facilities only represent a small percentage of the urban delivery truck traffic produced by businesses in most metropolitan areas. For 
instance, the Port of New York and New Jersey generate approximately 9,000 truck trips per day (Brom et al. 2009), which represent about 5.8 percent of Manhattan's daily truck traffic, or 2.6 percent of the city's total truck trips $(343,206)$. These facilities and the externalities they produce require that issues related to road access capacity, the concentration of the generated traffic on highway corridors, and the economic impacts on the surrounding communities among others be addressed. However, the objective of the paper is to identify and quantify the freight trip generation of other facilities, such as businesses or buildings that individually or collectively generate a large proportion of truck traffic. These large urban freight traffic generators (LTGs) may include government offices, colleges and universities, hospitals, and mixed-use buildings among others. In addition, and based on field visits and previous work conducted by the authors, the paper discusses city logistics initiatives that offer the greatest opportunity for implementation at these LTGs.

This paper is organized as follows. Section 2 provides context about LTGs and discusses the type of city logistics initiatives that could be considered to alleviate the externalities of the freight traffic produced and attracted by these LTGs. Section 3 introduces two effective and complementary procedures to identify these LTGs and describes implementation of these procedures using New York City as a case study. The paper ends with a conclusions section.

\section{Large urban freight traffic generators and opportunities for city logistics initiatives}

Large urban freight traffic generators (LTGs) can be defined as specific facilities housing businesses that individually or collectively produce and attract a large number of daily truck trips. Depending on the definition of "large traffic," and the facility type of interest, these large traffic generators could be identified in a number of different ways. Based on results from previous work, the authors identify them in two main groups. The first corresponds to a group of large buildings or landmarks that house scores of establishments, such as the Empire State Building. Although the establishments contained in the building could each generate small amounts of freight, the aggregate of the freight generated by the building as a whole translates into significant freight traffic. The second group involves large establishments (businesses) that, because of their size, generate significant amounts of freight. The following chapter illustrates the implementation of these two effective and complementary identification procedures.

In essence, these LTGs offer great opportunities for the development and implementation of city logistics initiatives. In general, city logistics encompass all strategies designed to improve the overall performance of movements of urban goods while mitigating the impacts of social and environmental externalities (Rodrigue et al. 2013). City logistics strategies usually involve cooperation between different agents, such as joint efforts between private and public sectors, or strategies to globally optimize logistics systems in urban areas. Examples include urban consolidation or transshipment centers, freight villages, central goods sorting points, co-operative delivery systems, off-hour delivery schemes and first/last mile solutions such as pick-up/drop-off locations which in turn may include reception/delivery boxes, collection points and locker-banks.

In terms of co-operative delivery systems, for example, these large buildings or businesses usually have central receiving stations that could easily accommodate coordinated deliveries. These would allow the LTGs to receive deliveries during the off-hours and then distribute the shipments to the consignees during regular hours, without causing major inconveniences to receivers (shipments going out of the facility could flow in the opposite way). In essence, the availability of centralized receiving stations makes LTGs great targets for the implementation of a variety of initiatives, such as off-hour delivery programs and consolidation strategies. Furthermore, though the spatial concentration of truck traffic in urban areas aggravates problems associated with urban goods movements (congestion, pollution), it could 
also offer great opportunities for initiatives such as parking and loading zone management and last mile distribution strategies. The following sections discuss these opportunities in more detail.

\subsection{Off-hour deliveries and centralized receiving stations}

Large urban freight traffic generators are well suited for the implementation of off-hour delivery programs. Imagine a large building such as Grand Central Station in New York City, where between 100 and 250 trucks arrive each day to deliver shipments to approximately 184 establishments. In the absence of a centralized receiving station each carrier needs to directly deliver the goods to its recipient stores. Deliveries are then constrained by the stores' hours of operations, delivery windows, and staff availability, among other considerations. More important, these separate deliveries create an unnecessary flow of equipment, goods and personnel inside the facilities. In contrast, when a centralized receiving station is allocated, deliveries to different stores can be received at one location, without time constraints, and shipments to the different stores can then be consolidated and distributed when most appropriate. Schematically, this concept is illustrated with the assistance of Figure 1.

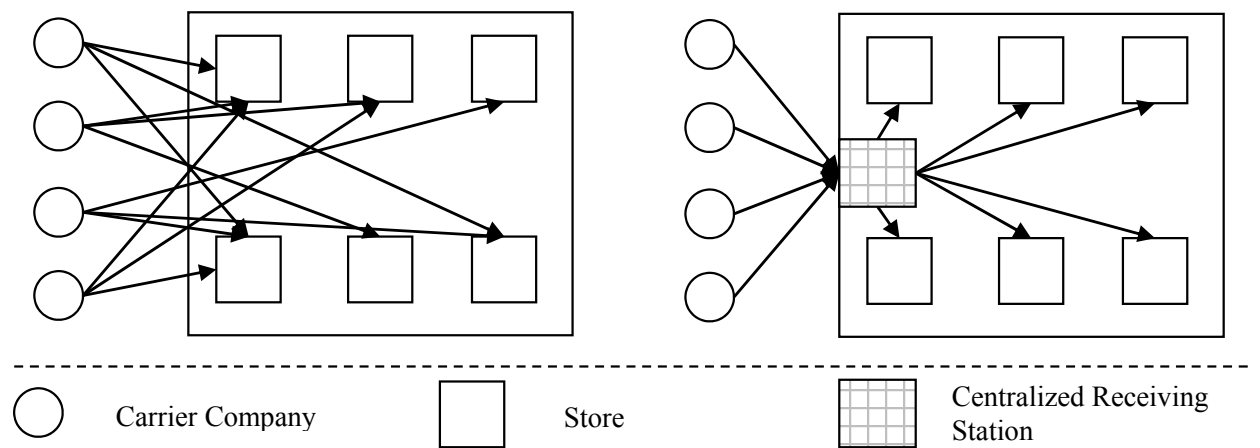

a) Direct shipments

b) Through receiving station

Figure 1: Schematic of centralized deliveries at large traffic generators.

Deliveries and truck trips are generally attracted and produced during regular hours since they are constrained by the hours of operations of the retailers. This reason has been identified by previous studies as one of the major constraints preventing carrier companies from shifting operations to the off-hours (New York State Thruway Authority 1998; Vilain and Wolfrom 2000; Holguín-Veras 2008; NICHES 2008). However, the central receiving station of large freight traffic generators would allow for the deliveries to be made to those businesses participating in an off-hour delivery program (OHD). Since the receivers are, for the most part, indifferent to how the shipments are transported as long as they arrive on time, it is fair to assume that, once liability issues are sorted out, most store owners would not object if their deliveries were brought to a central receiving station instead of directly to them.

It is important to mention that unlike smaller buildings and individual establishments, these large urban freight traffic generators are often managed by property management firms. These companies are responsible for the typical day-to-day building operations, such as tenant management, maintenance and security. In spite of the fact that these managers are responsible for the deliveries entering the buildings, a coordinated effort between property managers and the tenants as well as their supplier/carrier companies would be required for a successful participation in these types of strategies. In addition, some of these buildings or businesses may operate in high-value locations where space is at a premium. Therefore, some of these buildings may have minimal storage space for deliveries, and installing a large central receiving station may not be feasible, or the cost to be internalized by the management firm or the tenants may be too high. Space is also limited at individual establishments, reducing the inventory buffer that can be stored, and thus increasing the frequency of deliveries. For LTGs, space may be the 
most challenging barrier to overcome when implementing cargo-consolidation types of city logistics strategies.

To overcome some of these limitations, incentives (public and private) will be needed to enact participation in both OHD and the implementation of central receiving stations. For example, city authorities could provide exemptions from development ordinances that allow participants to use spaces for these activities, or even allow a higher floor-area ratio if they provide receiving or consolidating stations at the ground level. Moreover, additional incentives should be provided for retrofits of facilities or for the use of technologies, such as access and internal surveillance and control, to mitigate the risks associated with handling and storing goods. Incentives could be of the form of one-time financial incentives, discounts from carriers, tax breaks, public recognition programs, or the provision of business support services. Monetary incentives are a good way to foster a shift to OHD, as the case of New York City has shown.

Along the lines of receiving stations, and OHD programs, LTGs could implement a delivery and servicing plan (DSP) to manage the delivery and service trips produced or attracted. This plan, developed by Transport for London seeks improvements in the freight activities at buildings by: managing deliveries to reduce the number of trips; identifying the location and time for safe and efficient delivery activities; and promoting good practices (Transport for London 2013a). The implementation of this type of initiative has shown important reductions in the number of deliveries being made to a single location (between 20 and 40 percent), by fostering receiver-led consolidation and cooperation (Transport for London 2013b).

\subsection{Pick-up/drop-off points are unattendend deliveries}

Augereau and Dablanc (2008) define pick-up and drop-off points as local collection and distribution depots, or boxes, from which consumers can pick up goods ordered via home retail services (e.g., by mail, phone or the Internet). Although initial experiments with pick-up points were not successful, recent developments with relay points and drop-off boxes (e.g., Kiala relay points in France and Packstation locker banks in Germany) have produced different results (Augereau and Dablanc 2008).

Successful systems vary from networks of automated locker banks to storage points managed by local businesses. As such, locker bank/box systems can serve as centralized receiving stations without requiring staff. This offers great advantages, because commodities can be delivered and picked-up at any time. While a large bank system might not feasibly serve all the establishments of a large urban freight traffic generator, with combined implementation strategies, these systems can be installed in public or private spaces in or near these buildings or businesses quite effectively. In addition, close private spaces (e.g., parking lots) could be rented, or public facilities (e.g., service and transit stations) could be used for such centralized receiving stations. For a comparison of the different types of drop-off and collectionpoint alternatives, readers are referred to (BESTUFS 2007). Following these strategies from Europe, the United States Postal Service (USPS) conducted a pilot test in 2012 of the gopost parcel delivery locker concept (United States Postal Service 2013). These lockers are being located at different locations near USPS locations, grocery stores, pharmacies, transportation hubs, shopping centers and other locations. Similarly, Amazon is using a locker system as an alternative for delivery locations (Amazon 2013).

Given staffing and security considerations, LTGs are also ideal candidates for the implementation of other unattended delivery strategies. These would allow carriers to deliver goods during the off-hours, through double-door systems, virtual cages inside the establishments, or with the use of other video- or alarm-monitored equipment (Ogden 1992; Holguín-Veras et al. 2013). It may be important to complement these strategies with initiatives to decrease liability exposure issues. 


\subsection{Parking and loading-unloading initiatives for large urban frieght traffic generators}

Parking is a major issue in large urban areas, one that aggravates congestion and increases vehicle miles traveled. For example, in Manhattan a (passenger) vehicle spends about 9 minutes on average searching for a parking spot (Shoup 2005). And given specific requirements for freight deliveries, finding a parking spot close to the customer's location may require an even larger amount of time (or the lack of parking availability results in large levels of double or other illegal parking). As a result, it is important to implement parking and loading-unloading initiatives, which have been effective in reducing urban congestion and mitigating illegal parking and on-street unloading (Quak 2008; Nourinejad et al. 2013). Usually, these types of initiatives are easy to implement in the short term as they require low capital investments, and since they improve the efficiency of delivery operations, they enjoy great receptivity from carriers. These initiatives include: parking restriction, peak-hour clearways, parking pricing, reserved parking, low-scale nearby delivery areas, and on-street loading bays (Ogden 1992; Rizzo Associates 2001; Cambridge Systematics 2007; Jones et al. 2009; FREILOT 2010; NYC Department of City Planning 2011; PIARC 2011; Plumeau et al. 2012; Jaller et al. 2013). Given their size and establishment concentration, LTGs are well suited for the implementation of these types of initiatives.

Parking pricing, which involves time-of-day prices, is intended to increase turnover, optimize use of curb space, reduce traffic infractions, and reduce vehicles from circling the blocks by trying to maintain curb space availability. In this context, NYC is experimenting with market-rate pricing through its Smart Pilot Program (New York City Department of Transportation 2012) and the use of Muni-Meters (Cambridge Systematics 2007; NYC Department of City Planning 2011; Jaller et al. 2013). Although carriers are not always able to pass the increased parking costs onto their customers, if parking pricing programs result in increased parking availability, such a benefit would be well received by most carriers, whose average parking fines can be in excess of \$2,000 per month per truck (Holguín-Veras et al. 2005).

The areas near the LTGs could be the subject of this, and other types of parking pricing initiatives, which when implemented together with centralized receiving stations and off-hour delivery programs could have a huge positive impact in reducing externalities. Areas adjacent to these large buildings or businesses can be assessed for reserved parking or on-street loading bay initiatives (Ogden 1992 San Francisco County Transportation Authority 2009)—with time limits—or for the installation of urban transshipment platforms from which the last mile distribution to the different large buildings or establishments can take place using trolleys, carts, electric vehicles, or even bicycles. For instance, the NYCDOT has developed specific parking, standing and stopping rules for commercial vehicles (New York City Department of Transportation 2012; The City of New York 2012). These measures could easily be adjusted in terms of time constraints, types of vehicles and other equipment requirements to better fit the needs of LTGs.

\section{Indentification of large urban freight traffic generators}

As discussed in the previous section, this paper introduces two effective and complementary procedures to identify LTGs: large buildings or landmarks and large establishments. Furthermore, freight trip generation (FTG) models estimated by the authors were used to quantify the freight traffic generated by these LTGs. The FTG models were estimated using a trip generation dataset of about 400 receiver and 400 carrier companies in the New York City area. Ordinary least squares were used to estimate the disaggregate models at the establishment level based on employment. Table 2 shows the models for freight trips produced (FTP, truck-trips/day) and freight trips attracted (FTA, deliveries/day) for different industry sectors using the North American Industry Classification Systems (NAICS). Table 3 shows the ones estimated for different land-use categories considering the City of New York Zoning Resolution 
(NYCZR). It is important to make the distinction between FTA and FTP and inbound and outbound trips, especially for the cases where goods are not distributed through freight tours and the operators that are delivering the goods to an establishment differ from the ones transporting shipments from the establishment. For these cases, every delivery (FTA) generates an inbound loaded trip and one outbound empty trip, while every shipment (FTP) generates one inbound empty trip and one outbound loaded trip. Having a sense about the total amount of inbound and outbound trips requires summing both FTA and FTP. For other cases, it is necessary to have information about the logistical production and attraction patterns of the establishments. For these analyses, FTA and FTP include all the shipments (e.g., recycling, paper products, parcel, furniture and cleaning supplies) that are produced or attracted by the building/establishments. With the models and data for Manhattan, the remainder of this section illustrates the LTG identification process.

As discussed by Holguín-Veras et al. (2011), FTG is, in general, the result of logistical decisions that determine shipment size, type of mode or vehicle used, and the frequency of distribution. As a result, FTG may not necessarily depend on business size (employment). The estimates using the freight trip generation collected data, showed that only in a small proportion of the industries, the FTG was dependent on employment, with the majority being a constant per establishment or a combination of constant and a rate per employee (see Table 2 and Table 3). These models were validated with external datasets, and transferability analyses were conducted for other geographic locations. The results indicate that the models are transferable, thus a constant number of truck trips or deliveries could be expected to be produced or received by establishments in different industry sectors in urban areas. For a detailed description about the data, estimation process and additional FTG models (other industrial classification systems and land-use categories) the reader is referred to Holguín-Veras et al. (2011), Holguín-Veras et al. (2013), and Lawson et al. (2012). For a description of the transferability analyses and external validation of the models see Holguín-Veras et al. (2013).

Table 2: Freight trip generation models for industry segments.

\begin{tabular}{|c|c|c|c|c|}
\hline \multirow[b]{2}{*}{ NACIS/Description } & \multicolumn{2}{|c|}{ Freight Trip Attraction } & \multicolumn{2}{|c|}{ Freight Trip Production } \\
\hline & Intercept & Employment & Intercept & Employment \\
\hline Construction* & 2.160 & & & 0.068 \\
\hline 31 - Light Manufacturing & 2.400 & & 2.846 & \\
\hline 32 - Medium Manufacturing & 4.420 & & & 0.023 \\
\hline 33 - Heavy Manufacturing & 2.490 & & 1.750 & \\
\hline Manufacturing* & 2.831 & & 2.214 & \\
\hline Wholesale Trade* & 2.272 & 0.069 & 1.755 & 0.036 \\
\hline 44 - Furniture, food, beverage, tobacco, textile and others & 2.458 & 0.132 & 0.993 & 0.021 \\
\hline 45 - Wood, paper, printing, chemicals & 2.724 & & \multicolumn{2}{|c|}{$\mathrm{n} / \mathrm{a}$} \\
\hline Retail Trade* & 3.070 & 0.063 & & 0.161 \\
\hline 48 - Transportation and Warehousing ** & \multirow{2}{*}{\multicolumn{2}{|c|}{$\mathrm{n} / \mathrm{a}$}} & 2.725 & 0.038 \\
\hline Transportation and Warehousing* & & & 2.718 & 0.038 \\
\hline Accommodation and Food* & 1.307 & 0.081 & \multicolumn{2}{|c|}{$\mathrm{n} / \mathrm{a}$} \\
\hline
\end{tabular}

Notes: * Based on group models, ${ }^{* *}$ Except postal and courier services, and warehousing

NAICS $=$ North American Industry Classification System

Freight Trip Attraction $=$ Deliveries $/$ Day, Freight Trip Production $=$ Truck-Trips $/$ Day 
Table 3: Freight trip generation for land-use categories.

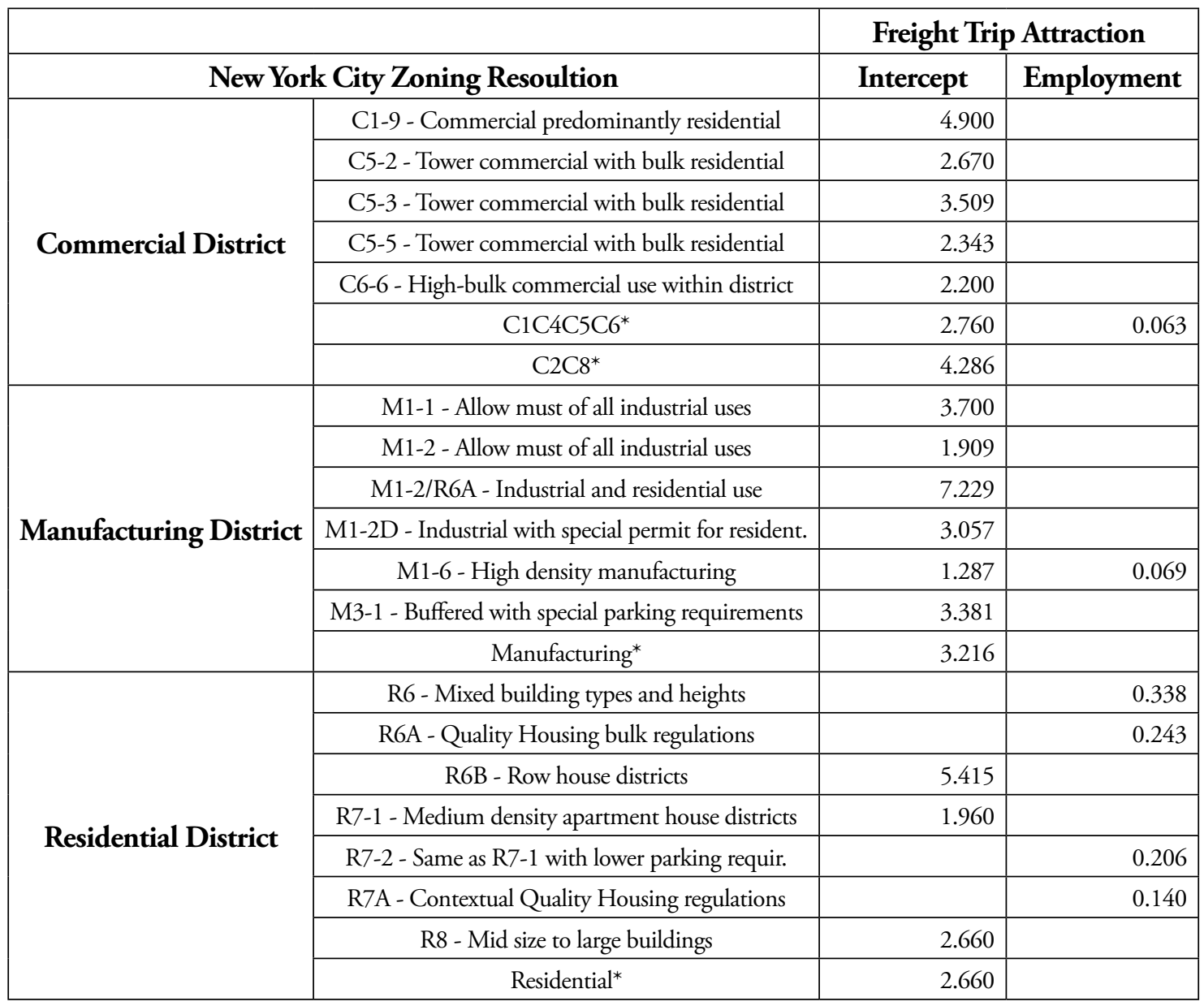

Notes: ${ }^{*}$ Based on group models. No data available to estimate freight trip production.

\subsection{Large buildings}

The first procedure focuses on large buildings or landmarks (e.g., Empire State, Grand Central Station). Most of these buildings are easily identifiable in Manhattan since they each have their unique ZIP code (identified by the USPS as single high-volume addresses). Fifty-six such LTGs were identified in New York City. As shown in Figure 2, the majority of them are located in the central business district (CBD) or south of Central Park (midtown and downtown Manhattan).

Using employment and establishment data from the ZIP Code Business Pattern Database (ZCBPD) (U.S. Census Bureau 2011) and the models from Table 2, Table 4 shows the truck trips produced and attracted by these LTGs. Approximately, the 7030 trips attracted and the 6761 daily truck trips produced represent 3.8 percent and 4.2 percent, respectively, of the city's daily FTG. 


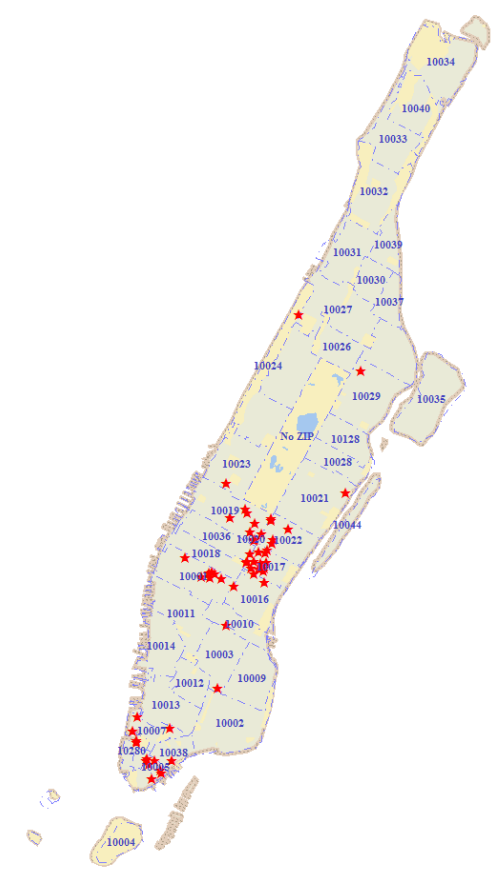

Figure 2: Location of large buildings and landmarks in Manhattan.

\subsection{Large establishments}

The second procedure identifies large establishments. Identifying them requires defining a measure of business size or other variables that capture the scale of the operations at the establishment. These variables have significantly different levels of explanatory power, depending on their inherent ability to capture the intensity of freight generation (FG) and FTG. As discussed by Holguín-Veras et al. (2011), FG is expected to be proportionally related to business size; however, there are other important logistics and economic considerations that affect the generation of truck traffic. Nevertheless, business size plays an important role in the number of freight trips generated. Considering the most common measures of business size used, the authors identify large establishments based on two different criteria: number of employees and area. This approach is important because it identifies large establishments that might otherwise go unnoticed since they usually do not have any landmark status. On the other hand, this method's drawback is that since official employment data are only available at the ZIP code level, no accurate geo-location is possible. (The authors recommend care when using employment information from commercial data aggregators.) 
Table 4: Large buildings and landmarks in Manhattan.

\begin{tabular}{|c|c|c|c|c|c|c|c|c|c|c|c|}
\hline \multirow[b]{2}{*}{ 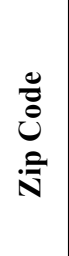 } & \multirow[b]{2}{*}{$\begin{array}{c}\text { Zip Code } \\
\text { Description }\end{array}$} & \multirow{2}{*}{ 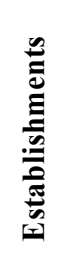 } & \multicolumn{3}{|c|}{ Estimated } & \multirow[b]{2}{*}{ 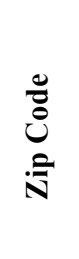 } & \multirow[b]{2}{*}{$\begin{array}{c}\text { Zip Code } \\
\text { Description }\end{array}$} & \multirow{2}{*}{ 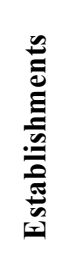 } & \multicolumn{3}{|c|}{ Estimated } \\
\hline & & & 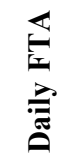 & 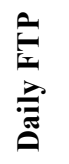 & 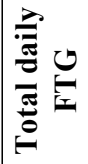 & & & & 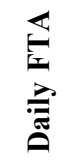 & 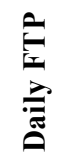 & 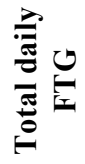 \\
\hline 10118 & Empire State Building & 594 & 1,014 & 898 & 1,912 & 10152 & Seagram Building & 88 & 98 & 101 & 200 \\
\hline 10165 & Lincoln Building & 462 & 573 & 546 & 1,119 & 10178 & 101 Park Avenue & 73 & 85 & 89 & 174 \\
\hline 10119 & 1 Penn Plaza & 300 & 460 & 454 & 914 & 10115 & 475 Riverside Drive & 66 & 79 & 71 & 150 \\
\hline 10170 & Graybar Building & 309 & 373 & 375 & 748 & 10069 & --- & 55 & 81 & 68 & 149 \\
\hline 10123 & 450 Fashion Avenue & 240 & 337 & 330 & 667 & 10104 & 1290 Avenue of the An & 36 & 69 & 68 & 137 \\
\hline 10166 & Met Life Building & 130 & 345 & 277 & 622 & 10171 & West Vaco Building & 54 & 64 & 71 & 135 \\
\hline 10282 & --- & 227 & 283 & 272 & 555 & 10041 & 55 Water Street & 39 & 81 & 46 & 127 \\
\hline 10112 & General Electric Buildi & 130 & 232 & 316 & 548 & 10154 & Bristol Myers Building & 52 & 66 & 61 & 127 \\
\hline 10107 & Fisk Building & 222 & 279 & 262 & 542 & 10172 & Chemical Bank Buildin & 57 & 62 & 63 & 125 \\
\hline 10120 & 112 W 34th Street & 68 & 332 & 198 & 530 & 10285 & Shearson American Ex] & 20 & 29 & 86 & 115 \\
\hline 10169 & Helmsley Building & 227 & 265 & 249 & 514 & 10105 & Burlington Building & 48 & 58 & 54 & 112 \\
\hline 10281 & --- & 153 & 263 & 239 & 502 & 10158 & 605 3rd Avenue & 49 & 51 & 56 & 107 \\
\hline 10103 & Tishman Building & 103 & 266 & 199 & 464 & 10270 & AIG & 46 & 57 & 49 & 106 \\
\hline 10122 & Pennsylvania Building & 169 & 235 & 227 & 463 & 10055 & Park Avenue Plaza & 44 & 44 & 49 & 93 \\
\hline 10168 & Grand Central Station & 184 & 241 & 221 & 462 & 10177 & Marine Midland Buildi & 33 & 39 & 46 & 85 \\
\hline 10110 & 500 5th Avenue & 177 & 226 & 205 & 431 & 10286 & Bank of New York & 40 & 43 & 41 & 84 \\
\hline 10155 & Architect \& Design & 140 & 253 & 166 & 419 & 10173 & 342 Madison Avenue & 30 & 39 & 41 & 80 \\
\hline 10111 & International Building & 164 & 208 & 193 & 401 & 10080 & Merrill Lynch & 29 & 32 & 32 & 64 \\
\hline 10106 & 888 Fashion Avenue & 118 & 182 & 147 & 329 & 10043 & CITIBANK & 29 & 30 & 31 & 61 \\
\hline 10121 & 2 Penn Plaza & 86 & 134 & 189 & 322 & 10162 & Pavilion Building & 17 & 23 & 26 & 49 \\
\hline 10174 & Chrysler Building & 125 & 149 & 164 & 313 & 10199 & GPO Official Mail & 5 & 30 & 9 & 39 \\
\hline 10153 & General Motors Buildit & 101 & 126 & 177 & 302 & 10102 & Radio City BRM & 9 & 24 & 13 & 37 \\
\hline 10167 & Bear Sterns Building & 118 & 147 & 142 & 288 & 10072 & Philip Morris & 5 & 25 & 7 & 32 \\
\hline 10279 & Woolworth Building & 117 & 132 & 150 & 282 & 10292 & Bache Halsey Stuart Sh & 14 & 14 & 14 & 28 \\
\hline 10176 & French Building & 103 & 143 & 124 & 268 & 10081 & JP Morgan Bank & 12 & 12 & 13 & 25 \\
\hline 10175 & 521 5th Avenue & 92 & 129 & 110 & 239 & 10278 & Jacob K. Javits & 7 & 7 & 9 & 16 \\
\hline 10271 & Equitable Building & 93 & 104 & 103 & 207 & 10179 & Bear Sterns Building & 7 & 7 & 7 & 14 \\
\hline 10151 & 745 5th Avenue & 72 & 103 & 102 & 205 & 10260 & JP Morgan Bank & 6 & 6 & 6 & 12 \\
\hline & & & & & & & Total & 4,912 & 7,030 & 6,761 & 13,791 \\
\hline
\end{tabular}

Notes: FTA $=$ Freight Trips Attracted, FTP $=$ Freight Trips Produced

\subsubsection{Employment}

Data from the ZCBPD (U.S. Census Bureau 2011) can be used to select ZIP codes that have establishments with large numbers of employees (e.g., 250, 500, and 1000+). Furthermore, using freight trip generation models, aggregate truck traffic can be estimated. Table 5 shows a summary of the freight trips generated by the establishments for different ranges of employment size. For illustration purposes, the employment levels chosen for the analyses are between 250 and 499, 500 to 999, and more than 1000 employees. As shown, 13,542 establishments have between 250 and 499 employees, representing 13.2 percent of the city's total establishments and about 14.1 percent and 15 percent of the total deliveries received and truck trips produced, respectively. It is important to mention that these establishments also 
have a large share of the city's total employment, representing around 34.24 percent. In addition, there are 6203 (6.05 percent) establishments with between 500 and 999 employees, which account for almost 24 percent of the total employment and about 6 percent of the total freight trips generated. Finally, 4,922 (4.8 percent) of establishments have more than 1000 employees, accounting for another quarter of the city's employees and about 3.53 percent of city's total daily deliveries received. As these numbers show, these large establishments represent a quarter of the city's establishments, and yet account for about 84 percent of its total employment (see Table 1). Furthermore, these numbers evidence the discussion in Holguín-Veras et al. 2011, where FTG is not proportionate with employment since 84 percent of total employment only accounts for about 25 percent of total FTG. Although these large establishments may generate additional truck trips not estimated with the available FTG models, these values provide insight about the magnitude of the FTA and FTP. Due to this limitation, for these large establishments the estimated FTG could represent a lower bound.

Table 5: Large establishments by employment.

\begin{tabular}{|l|r|r|r|r|r|}
\hline & $\begin{array}{c}\text { No. of } \\
\text { ZIP Codes }\end{array}$ & Establishments & $\begin{array}{c}\text { Estimated } \\
\text { employment }\end{array}$ & \multicolumn{1}{c|}{$\begin{array}{c}\text { Estimated } \\
\text { daily FTA }\end{array}$} & \multicolumn{1}{c|}{$\begin{array}{c}\text { Estimated } \\
\text { daily FTP }\end{array}$} \\
\hline Large Establishments* & & 24,667 & $1,732,875$ & 43,224 & 40,274 \\
\hline $\mathbf{2 5 0 - 4 9 9}$ employees & 65 & 13,542 & 706,010 & 25,796 & 24,093 \\
\hline $\mathbf{5 0 0 - 9 9 9}$ employees & 52 & 6,203 & 493,294 & 10,982 & 8,866 \\
\hline $\mathbf{1 0 0 0 + \text { employees }}$ & 53 & 4,922 & 533,571 & 6,446 & 7,314 \\
\hline
\end{tabular}

* Estimates based on FTG models developed by the authors.

LTGs could generate additional truck trips (estimates provide a lower bound).

Figure 3 shows the spatial distribution of these establishments. Since only ZIP code data was available, the exact geo-location of the individual establishments is not shown. However, understanding the spatial aggregation of these large establishments would be useful for planners. In Manhattan, for instance, it is clear that the largest concentrations of large establishments correspond to Midtown Manhattan. In addition, when employment information is available for individual establishments, FTG models can be used to identify critical employment levels for establishments in different industries.

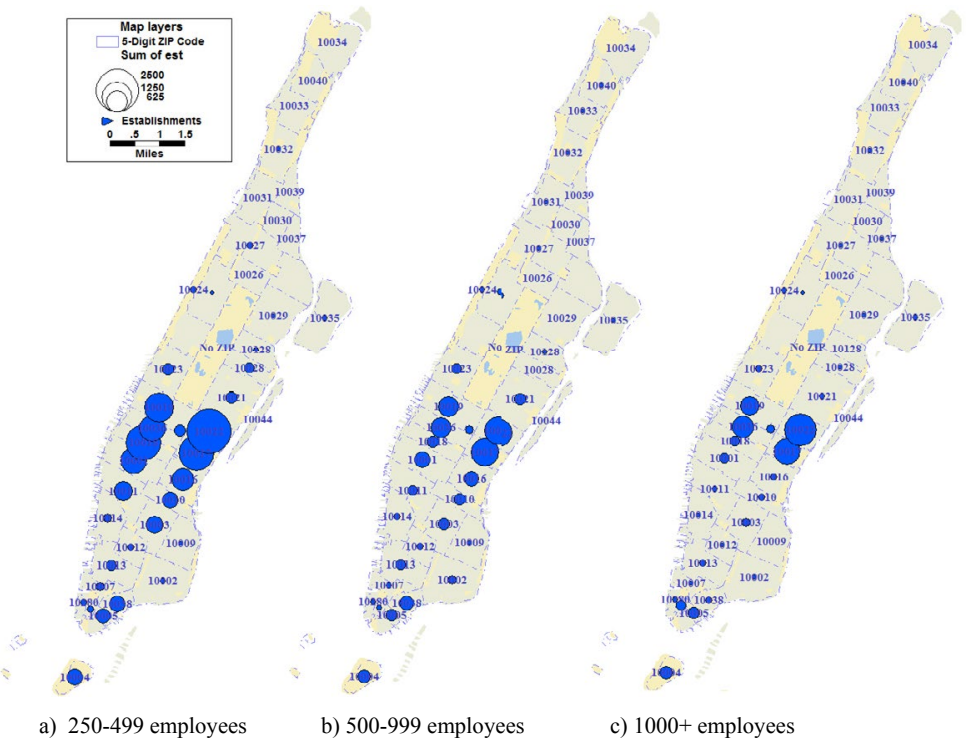

Figure 3: Geo-location of ZIP Codes with large establishments selected by employment. 


\subsection{2}

Commercial area

This section introduces the identification procedure based on area (i.e., commercial square footage). The area data for Manhattan was obtained from the tax parcel PLUTO dataset (New York City Department of City Planning 2011), which contains information for 43,316 parcels in the Manhattan area. These parcels were ranked based on the total square footage of "commercial" use, as previous research found this group to be highly correlated to business employment (Holguín-Veras et al. 2013). After analyzing the distribution of the commercial areas, the authors selected the top 0.5 percent largest areas (between 797,477 and $17,616,756$ sq. $\mathrm{ft}$.) as the preliminary candidates for large establishments. This 0.5 percent corresponds to 146 tax parcels with an estimated 20,778 establishments (20.25 percent of the city's total), accounting for 22.66 percent of the total city employment. These 146 parcels are likely to generate a larger number of freight trips. In Figure 4, the color scale indicates the ranking of commercial square footage, and the parcels highlighted (in pink) with the cross symbol are the LTGs in Midtown and Downtown Manhattan. Most of these large establishments are (individual or groups of) high-rise building complexes with mixed-use commercial and office space. For example, Rockefeller Plaza, located between 48th and 51st streets, is a complex of 19 commercial buildings with a commercial area of 5,080,345 sq. ft., ranking it the largest in Manhattan. Another example is 55 Water Street, which houses hundreds of corporations. The Empire State Building is a 102-story skyscraper, with such residents as Walgreens and Starbucks, among others, with a total area for commercial use of 2,812,739 sq. $\mathrm{ft}$. Figure 4 shows the location of these buildings.

Empirical results using the FTG models from Table 3 and the NYCZR land-use category for each of the parcels indicate that they attract 67,949 daily truck trips, or about 37 percent of the city's total FTAs.

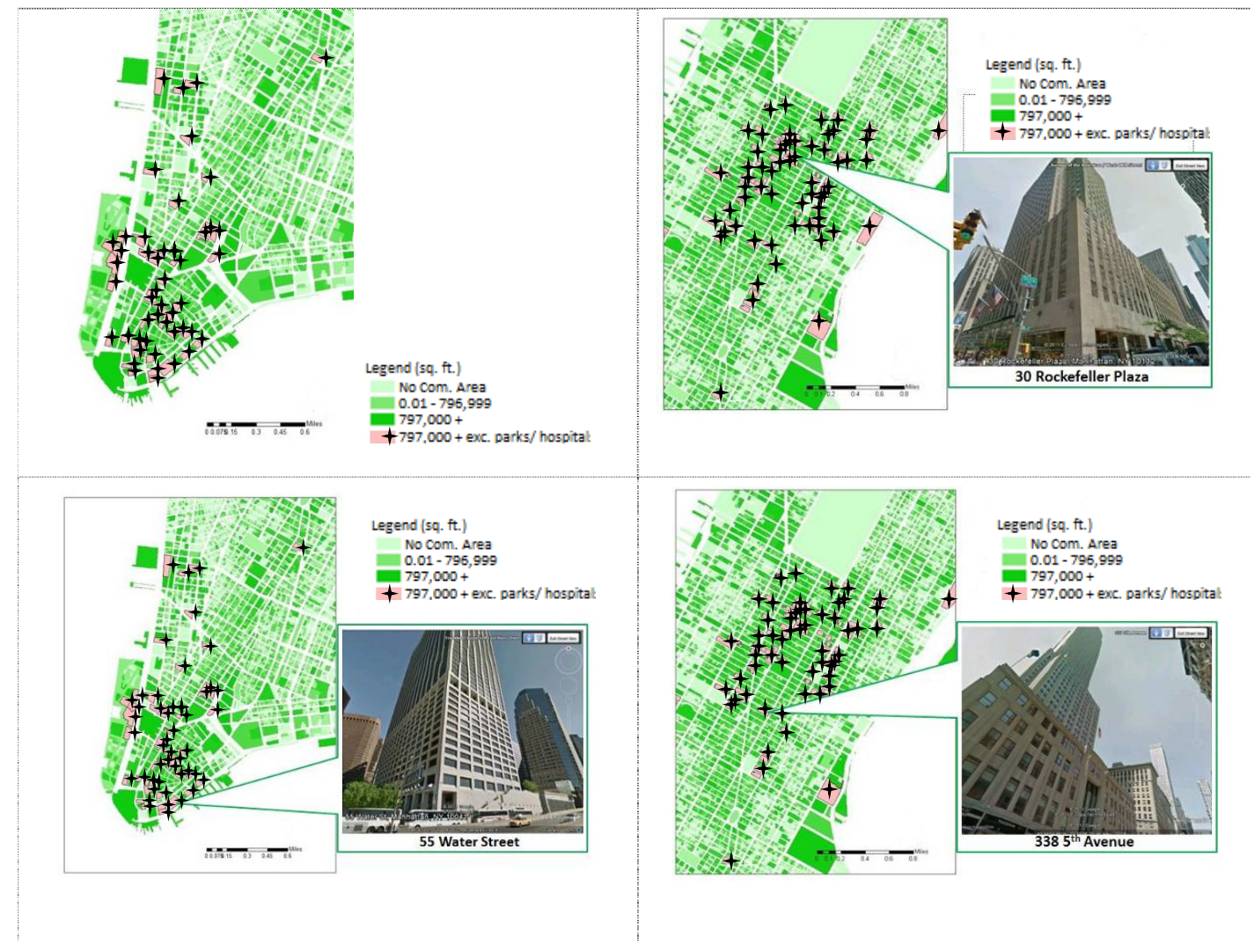

Figure 4: Large parcels and establishments by commercial area. 


\subsection{Summary of results from the identification procedures}

Large urban freight traffic generators have been identified based on three main criteria: (1) large building and landmarks, (2) large establishments defined by employment size, and (3) large establishments based on commercial area. Although these analyses have been performed for Manhattan, the procedures can be used for other urban areas. Table 6 shows a comparison of the selection results and the total establishment population in Manhattan. These results have important planning implications as they show that a limited and small number of facilities (i.e., large buildings and establishments) generate a considerable number of freight trips.

As discussed, the 56 LTGs selected as large buildings (a very small number of the city's total buildings) account for about 4 percent of the city's total freight trips generated. This makes them ideal candidates for city logistics initiatives. The other two criteria are also effective in identifying large establishments that can be expected to generate a large proportion of freight and freight trips generated. While large establishments selected by employment size represent about 25 percent of the city's FTG, the parcels selected by commercial area account for almost 37 percent of the daily freight trips attracted. It is important to mention that research (Holguín-Veras et al. 2013) has shown that there is a high statistical relationship between employment and commercial area, so it can be expected that the LTGs identified by these two criteria overlap; however, data limitations do not allow for their individual identification.

Table 6: Comparison between the region and the LTGs identified.

\begin{tabular}{|l|r|r|r|r|r|r|r|r|r|}
\hline & No. & Establishments & \%*** & $\begin{array}{c}\text { Estimated } \\
\text { employment }\end{array}$ & \%*** & $\begin{array}{c}\text { Estimated } \\
\text { daily FTA }\end{array}$ & \%*** & $\begin{array}{c}\text { Estimated } \\
\text { daily FTP }\end{array}$ & \%*** \\
\hline Manhattan & & 102,597 & & $2,062,079$ & & 182,427 & & 161,144 & \\
\hline Landmarks & 56 & 5,994 & $5.84 \%$ & 196,497 & $9.53 \%$ & 7,030 & $3.85 \%$ & 6,761 & $4.20 \%$ \\
\hline Large Establishments & & & 24,667 & $24.04 \%$ & $1,732,875$ & $84.04 \%$ & 43,224 & $23.69 \%$ & 40,274 \\
\hline 250-499 employees & & 13,542 & $13.20 \%$ & 706,010 & $34.24 \%$ & 25,796 & $14.14 \%$ & 24,093 & $14.95 \%$ \\
\hline 500-999 employees & & 6,203 & $6.05 \%$ & 493,294 & $23.92 \%$ & 10,982 & $6.02 \%$ & 8,866 & $5.50 \%$ \\
\hline $1000+$ employees & & 4,922 & $4.80 \%$ & 533,571 & $25.88 \%$ & 6,446 & $3.53 \%$ & 7,314 & $4.54 \%$ \\
\hline Large Area Parcels & 146 & 20,778 & $20.25 \%$ & 467,350 & $22.66 \%$ & 67,949 & $37.25 \%$ & $* *$ & \\
\hline
\end{tabular}

* More than 5 establishments

** No models available

FTA $=$ Freight Trips Attracted

*** Percentage from total values for Manhattan

FTP $=$ Freight Trips Produced

In general, the analyses also showed a spatial concentration of large establishments (both by employment and area) in the midtown and downtown areas. As expected these areas also show high congestion levels of both passenger and commercial vehicles. Furthermore, a recent study of parking requirements for freight activity in New York City found that the largest occupancy rates (function of demand over capacity) of on-street parking also correspond to Midtown and Lower Manhattan (Jaller et al. 2013).

Despite the benefits of allowing the identification of LTGs, there are some limitations to the analyses worth discussing. First, because of their size and characteristics, LTGs could be outliers, which indicate the need for further research to identify potential implications for freight trip generation modeling. The data used to estimate the freight trip generation models discussed in this paper covered a wide range of establishment sizes for different industries, and the transferability and validation analyses of the models provided positive results. However, research is still needed to improve the models so that they fully account for the freight trip generation patterns of LTGs. Due to this limitation, the current models may only be able to provide an indication of the lower bound of the freight trips produced and attracted by the LTGs. Second, the available freight trip generation data only allowed for the estimation of disaggregate models at the establishment level for broad industry classification (two-digit NAICS) 
and land-use types. Freight data is needed to be able to estimate more detailed models. And third, there are issues with the employment data provided by the ZCBPD, such as the headquarter effect, which can impact the analyses. The headquarter effect refers to the fact that some establishments, when surveyed by the Census Bureau, report aggregate economic information for the whole company. However, although there are issues with the ZCBPD, it is public data, and there are no other data sources that could provide this type of information.

\section{Conclusions}

This paper discusses the role of clusters of ordinary businesses or buildings in the generation of significant truck traffic. Since these LTGs produce highly concentrated traffic impacts, they also offer great opportunities for the implementation of a broad range of city logistics strategies. These strategies include: off-hours delivery programs; installation of central receiving stations; the use of pick-up/drop-off points or other unattended delivery options; access management; and, parking and loading/unloading initiatives.

LTGs' most salient advantages for city logistics are: their concentration of a large number of establishments in a reduced set of locations; the significant share of the daily truck traffic they attract and generate; their close spatial location, which allows for green logistics strategies (e.g., electric vehicles) for the last mile distribution; and, their size and commercial activity, which can benefit from economies of scale if receiver-led cargo consolidation is implemented. It is expected that the characteristics of LTGs could make dedicated consolidation facilities feasible for these buildings, despite the issues experienced by urban consolidation centers (in terms of high investment and operational cost, carrier participation and effectiveness). At the same time, some of the advantages of LTGs, at least in New York City, could also prove to be practical disadvantages for city logistic strategies, such as lack of storage space for the large volume of goods, security management, and limited loading facilities leading to increased scheduling complexities. However, it is important to develop incentive strategies to foster the implementation of these initiatives; and there may be opportunities at other geographic areas where the introduction of city logistics alternatives are warranted. As a result, it is important to conduct detailed analyses of specific locations and LTGs to take full advantage of the opportunities provided for city logistics initiatives.

In addition, the paper described and compared different procedures that can be used in different urban areas to identify LTGs: (1) large buildings and landmarks that house a large number of establishments and (2) large establishments, defined by employment size or area. Although different procedures select LTGs from different perspectives, leading to different lists of LTG candidates, all procedures indicate that, while limited in number, LTGs are greatly influential in terms of overall urban freight activity.

In summary, LTGs can be viewed as urban container terminals and ports: a limited number of buildings and establishments that produce and attract a large number of truck trips. Not only can these be easily identified, they have great potential to help improve the efficiency of freight deliveries in urban areas. The information presented in this paper can be expected to offer valuable insights to researchers and practitioners interested in urban freight system management.

\section{Acknowledgements}

This research was partially supported by the National Freight Cooperative Research Program and the National Cooperative Highway Research Program's project NCFRP 25 (jointly funded NCHRP 80) Freight Trip Generation and Land Use; the U.S. Department of Transportation project Integrative Freight Demand Management in the New York City Metropolitan Area-Implementation Phase; and the Volvo Research and Educational Foundation's Center of Excellence for Sustainable Urban Freight Systems. The support and contributions of these sponsors are both acknowledged and appreciated. 


\section{References}

Allen, J., S. Anderson, M. Browne, and P. Jones. (2000). A Framework for Considering Policies to Encourage Sustainable Urban Freight Traffic and Goods/service Flows. Summary report. Transport Studies Group, University of Westminister, UK.

Allen, J., G. Tanner, M. Browne, S. Anderson, G. Christodoulou, and P. Jones. 2003. Modelling Policy Measures and Company Initiatives for Sustainable Urban Distribution. Transport Studies Group, University of Westminster. URL: http://www.wmin.ac.uk/transport.

Amazon. 2013. AmazonLocker. URL: http://www.amazon.com/b/?node=6442600011\&ref=locker_ fd_brws.

Augereau, V., and L. Dablanc. 2008. An evaluation of recent pick-up point experiments in European cities: The rise of two competing models? In Innovations in City Logistics. Edited by E. Taniguchi and R. Thompson. Hauppauge, NY: Nova Science Publishers.

BESTUFS. 2007. Good Practice Guide on Urban Freight Transport. URL: http://www.bestufs.net/.

Brom, M., C. González, J. Holguín-Veras, and J. Collura. (2009, October). Congestion: Are ports the one to blame for urban congestion? Presentation conducted at Third METRANS National Urban Freight Conference, Long Beach, CA.

Bureau of Transportation Statistics. 2010. Transportation Statistics Annual Report. URL: http://www.bts. gov/publications/transportation_statistics_annual_report/2010/pdf/entire.pdf.

Cambridge Systematics. 2007. Increase cost of parking in the Manhattan central business district (CBD). Technical memorandum prepared for New York City Economic Development Corporation and the New York City Department of Transportation. URL: https:/www.dot.ny.gov/programs/ repository/Tech\%20Memo\%20on_Parking.pdf.

Dablanc, L. 2007. Goods transport in large European cities: Difficult to organize, difficult to modernize. Transportation Research Part A: Policy and Practice 41(3): 280-285.

Dablanc, L., G. Guiliano, K. Holliday, and T. O’Brien. 2013. Best practices in urban freight management: Lessons from an international survey. Transportation Research Board 92nd Annual Meeting, Washington, D.C., Jan. 13-17, 2013.

FREILOT. 2010. Urban freight energy efficiency pilot. URL: http://www.freilot.eu/en/home/.

Geroliminis, N., and C. F. Daganzo. 2005. A Review of Green Logistics Schemes Used in Cities Around the World. Berkeley, CA: University of California Berkeley Center for Future Urban Transport.

Holguín-Veras, J. 2008. Necessary conditions for off-hour deliveries and the effectiveness of urban freight road pricing and alternative financial policies in competitive markets. Transportation Research Part A: Policy and Practice 42(2): 392־-413.

Holguín-Veras, J., J. Amaya, M. Jaller, C. Wang, J. Wojtowicz, C. González-Calderón, I. Sánchez-Díaz, S. Hodge, M. Browne, E. Rhodes, and D. Haake. 2014a. Public sector freight strategies in metropolitan areas II: Pricing, logistics, and demand management. Transportation Research Board 93rd Annual Meeting, Washington, DC, Jan. 12-16, 2014.

Holguín-Veras, J., M. Jaller, J. Amaya, C. Wang, C. González-Calderón, I. Sánchez-Díaz, M. Browne, J. Wojtowicz, S. Hodge, E. Rhodes and D. Haake. 2014b. Public sector freight strategies in metropolitan areas I: Governance, supply side, and traffic operations. Transportation Research Board 93rd Annual Meeting, Washington, DC, Jan. 12-16, 2014.

Holguín-Veras, J., M. Jaller, L. Destro, X. Ban, C. Lawson, and H. Levinson. 2011. Freight generation, freight trip generation, and the perils of using constant trip rates. Transportation Research Record 2224: 68-81. 10.3141/2224-09

Holguín-Veras, J., M. Jaller, I. Sanchez, J. Wojtowicz, S. Campbell, C. Lawson, H. Levinson, E. Levine- 
Powers, and L. Tavasszy. 2013. Freight Trip Generation and Land Use: Final Report. URL: http:// onlinepubs.trb.org/onlinepubs/nchrp/nchrp_rpt_739.pdf.

Holguín-Veras, J., J. Polimeni, B. Cruz, N. Xu, G. List, J. Nordstrom, and J. Haddock. 2005. Off-peak freight deliveries: Challenges and stakeholders' perceptions. Transportation Research Record 1906: $42-48$.

Holguín-Veras, J., I. Sánchez-Díaz, C. Lawson, M. Jaller, S. Campbell, H. S. Levinson, and H. S. Shin. 2013. Transferability of freight trip generation models. Transportation Research Record 2379: 1-8.doi: 10.3141/2379-01.

Holguín Veras, J., R. Marquis, S. Campbell, J. Wojtowicz, X. Wang, M. Jaller, S. Hodge, S. Rothbard, and R. Goevaers. 2013. Fostering the use of unassisted off-hour deliveries: Operational and lownoise truck technologies. Transportation Research Record 2379: 56-63.doi: 10.3141/2379-07

Jaller, M., J. Holguín-Veras, and S. D. Hodge. 2013. Parking in the city: Challenges for freight traffic. Transportation Research Record 2379: 46-56.

Jones, E., A. Chatterjee, and R. Marsili. 2009. A collaborative plan for curbside freight delivery in Washington, D.C. ITE Journal 79(5): 22-25.

Kjaersgaard, S., and H. Jensen. 2003. Sustainable City Logistics Solutions. Madeira, Portugal: City Logistics III.

Lawson, C., J. Holguín-Veras, I. Sánchez-Díaz, M. Jaller, S. Campbell, and E. Powers. 2012. Estimated generation of freight trips based on land use. Transportation Research Record 2269: 65-72. $10.3141 / 2269-08$

New York City Department of City Planning. 2011. MapPLUTO. New York: NYC Department of Planning.

New York City Department of Transportation. 2012. Park Smart. URL: http://www.nyc.gov/html/dot/ $\mathrm{html} /$ motorist/parksmart.shtml.

New York State Thruway Authority. 1998. Commercial Vehicle Survey Final Report. Albany, NY: New York State Thruway Authority.

NICHES. 2008. Innovative Approaches in City Logistics: Inner-City Night Delivery. URL: http://www. niches-transport.org/fileadmin/archive/Deliverables/D4.db_5.8_b_PolicyNotes/14683_pn7_ night_delivery_ok_low.pdf.

Nourinejad, M., A. Wenneman, K. Nurul Habib, and M. Roorda. 2013. Truck parking in urban areas: Application of choice modelling within traffic simulation. Canadian Transport Research Forum, Halifax, Nova Scotia, Canada, June 10-12, 2013.

NYC Department of City Planning. 2011. Parking Best Practices: A Review of Zoning Regulations and Policies in Select US and International Cities. New York: NYC Department of City Planning, Transportation Division.

Ogden, K. W. 1992. Urban Goods Movement: A Guide to Policy and Planning. Brookfield, VT: Ashgate Publishing Company.

PIARC. 2011. Public Sector Governance of Urban Freight Transport. Paris: The World Road Association.

Plumeau, P., M. Berndt, P. Bingham, R. Weisbrod, S. Rhodes, J. Bryan, T, Cherrett. 2012. NCFRP Report 14: Guidebook for Understanding Urban Goods Movement. Washington, DC: The National Academies Press, Transportation Research Board.

Quak, H. 2008. Sustainability of urban freight transport: Retail distribution and local regulations in cities. Ph.D. dissertation. Rotterdam, Netherlands: University of Rotterdam, Erasmus Research Institute of Management (ERIM).

Rizzo Associates. 2001. Access Boston 2000-2010: Parking In Boston. First Edition. Boston: City of Boston. 
Rodrigue, J. P., C. Comtois, and B. Slack. 2013. The Geography of Transport Systems. London: Routledge. San Francisco County Transportation Authority. 2009. On-Street Parking Management and Pricing Study: Final Report. URL: http://www.sfcta.org/sites/default/files/content/Planning/ParkingManagementStudy/pdfs/parking_study_final.pdf.

Shoup, D. 2005. The High Cost of Free Parking. Chicago: American Planning Association.

Sousanis, J. 2011. August 15, 2011. World vehicle population tops 1 billion units. WardsAuto. URL: http://wardsauto.com/ar/world_vehicle_population_110815.

START. 2009. Start Final Report: Future Solutions for Goods Distribution. URL: www.start-project. org.

SUGAR. 2011 City Logistics Best Practices: A Handbook for Authorities. URL: http://www.sugarlogistics. eu.

Texas Transportation Institute. 2011. 2011 Urban Mobility Report. URL: http://mobility.tamu.edu/ ums/report/.

The City of New York. 2012. New York City traffic rules and regulations: Chapter 4 of Title 34 of the Rules of the City of New York. Albany, NY: NY State Deparment of Transportation.

Transport for London. 2013a. Delivery Servicing Plans. URL: http://www.tfl.gov.uk/microsites/freight/ delivery_servicing_plans.aspx.

Transport for London. 2013b. A Pilot Delivery Servicing Plan for TfL's Palestra Offices in Southwark: A Case Study. URL: http://www.tfl.gov.uk/microsites/freight/documents/20090921-DSP-PalestraCase-Study.pdf.

U.S. Census Bureau. 2011. Zip Code Business Patterns. URL: http://www.census.gov/epcd/www/ zbp_base.html.

United States Postal Service. 2013. USPS gopost. URL: https:/gopost.usps.com/go/EPLAction!input.

Vilain, P., and P. Wolfrom. 2000. Value pricing and freight traffic: Issues and industry constraints in shifting from peak to off-peak movements. Transportation Research Record 1707: 64-72. 